\title{
Editorial
}

\section{Kay Ferres}

k.ferres@griffith.edu.au

This issue's cover image, 'Parallel Universe: Stones Corner', comes from the Museum of Brisbane exhibition, Navigating Norman Creek. Trish FitzSimons created a series of short documentaries that reveal the natural and social ecosystems sustained by Norman Creek, even as the city encroaches ever closer and more densely. The overhanging branches of her arresting image form a barrier that protects the stream, its wildlife and the local people who use the creek for recreation and dreaming. It also suggests that this place has survived because there is something impenetrable about it. This image sets up a theme about habitat and dwelling that loosely links the essays in this issue.

The first group of articles explores the interaction of people and landscape in a variety of ways. Jodi Frawley describes how government encouraged small private enterprises to solve the environmental hazard that was prickly pear. This pest invaded a vast tract of land in central and western Queensland, preventing agricultural development. This story has lessons for contemporary environmental and economic policy. Jessica Carniel reads two autobiographical accounts of the wartime internment of Italian migrants in Queensland to demonstrate how policies of assimilation and multiculturalism allowed these men to take up different ideas of their Italian and Australian identities. This story is complicated by the fact that there was no 'Australian' citizenship until after World War II; rather, Australians were still British subjects. Jane Frank explores book culture in Maleny to consider how this township in the Sunshine Coast hinterland can benefit from city visitors and 'slow tourism', while sustaining the 'alternative' ethos enjoyed by its permanent residents. Sue Lovell unlocks the code of Vida Lahey's memorial tribute to her friend Madge Roe to reveal a vigorous young woman as well as an accomplished illustrator. At 'Roe's Kamp' on Stradbroke Island, her father had established an outdoor annexe where his grammar school students could develop the virtues of muscular citizenship that the newly federated nation required. But the story of Madge shows how this also offered opportunities for new forms of femininity to take shape.

This issue also includes an extended consideration of the work of Andrew McGahan, a Queensland-born writer who made his early reputation with novels set in Brisbane and on the western Darling Downs. Interviewing McGahan, Pete Walsh asks probing questions about his 'creative process', adding his own reflections on both the answers and McGahan's writing. In 'Going for Grunge', Sharyn Pearce revisits 1988 and 'Kill the Old', which both engage with public celebrations of the bicentennial, and the idea of the Australian nation, while Stephanie Green examines how McGahan uses the Gothic in The White Earth, to think about white claims to land and the legitimacy of ownership in light of the Mabo decision. 